\title{
Rational Design of an Organometallic Glutathione Transferase Inhibitor**
}

\author{
Wee Han Ang, Lorien J. Parker, Anastasia De Luca, Lucienne Juillerat-Jeanneret, \\ Craig J. Morton, Mario Lo Bello, Michael W. Parker, and Paul J. Dyson*
}

Glutathione transferases (EC 2.5.1.18; GSTs) catalyze the nucleophilic attack by reduced glutathione (GSH) on nonpolar compounds with electrophilic centers, acting on a range of exogenous substances (e.g. carcinogens and cancer chemotherapeutic agents) as well as endogenous compounds, forming part of a coordinated defense strategy to remove GSH conjugates from the cell. ${ }^{[1]}$ In mammals, there are two major families of soluble GSTs, located in the cytosol and mitochondria. These enzymes are dimeric proteins that can be grouped into at least eight gene-independent classes on the basis of their primary structure. ${ }^{[2-5]}$ Their three-dimensional structures do not differ significantly despite low sequence homology ${ }^{[6,7]}$ yet the different classes display a broad range of functions. ${ }^{[8-11]}$

[*] Dr. W. H. Ang, Prof. P. J. Dyson

Institut des Sciences et Ingénierie Chimiques

Ecole Polytechnique Fédérale de Lausanne (EPFL)

1015 Lausanne (Switzerland)

E-mail: paul.dyson@epfl.ch

L. J. Parker, Dr. C. J. Morton, Prof. M. W. Parker

Biota Structural Biology Laboratory

St. Vincent's Institute of Medical Research

9 Princes Street, Fitzroy, Victoria 3065 (Australia)

A. De Luca, Prof. M. Lo Bello

Department of Biology, University of Rome Tor Vergata

Via della Ricerca Scientifica snc, Rome 00133 (Italy)

Dr. L. Juillerat-Jeanneret

University Institute of Pathology

Centre Hospitalier Universitaire Vaudois (CHUV)

1011 Lausanne (Switzerland)

L. J. Parker, Prof. M. W. Parker

Department of Biochemistry and Molecular Biology

Bio21 Molecular Science and Biotechnology Institute

The University of Melbourne

30 Flemington Road, Parkville, Victoria 3010 (Australia)

[***] We thank Mike Gorman and Guido Hansen for advice and encouragement and Julian Adams for help at the Australian Synchrotron. This work was supported by the Australian Synchrotron Research Program, which is funded by the Commonwealth of Australia under the Major National Research Facilities Program. Use of the Advanced Photon Source was supported by the U.S. DOE, Basic Energy Sciences, Office of Energy Research. This work was also supported by grants from the Australian Research Council (ARC) and the Australian Cancer Research Foundation. L.J.P was supported by a National Health and Medical Research Council of Australia (NHMRC) Dora Lush Scholarship and an International Centre for Diffraction Data Crystallography Scholarship. M.W.P. is an ARC Federation Fellow and NHMRC Honorary Fellow. The Swiss National Science Foundation also provided financial support.

porting information for this article is available on the WWW under http://dx.doi.org/10.1002/anie.200900185.
The close similarity in the GST structure between the classes extends to the active site, which contains a very similar binding site for GSH (G-site) but a less similar binding site for the hydrophobic cosubstrate (H-site) where structural differences confer a degree of substrate selectivity among the isozymes. ${ }^{[6,7]}$ GST Pi class (GST P1-1) possesses two solventaccessible cysteine residues that affect catalytic activity when modified: Cys47 is located near the G-site and is critical for maintaining the conformation and stability of the G-site, ${ }^{[12]}$ and Cys101 is located at the dimer interface and can form a disulfide bridge with Cys47, requiring a large-scale conformational change of the active site leading to inactivation of the enzyme. ${ }^{[12]}$

GST P1-1 is often found in solid tumors, and its overexpression after exposure to antitumor drugs has been reported $;^{[11]}$ it is therefore a preferential anticancer drug target among the different GST isoenzymes. Ethacrynic acid (EA) is an effective GST inhibitor, particularly with GST P11, where it binds competitively to the $\mathrm{H}$-site; it has been investigated as a potential anticancer drug. ${ }^{[12]}$ Notably, when EA is bound productively at the $\mathrm{H}$-site, the $\alpha$-acetic moiety is directed into the protein interior, towards the interface of the protein dimer.

Transition-metal complexes based on ruthenium have been intensively investigated as anticancer drugs and have a strong propensity to react with soft nucleophilic centers such as thiol groups. ${ }^{[13-17]}$ Ruthenium compounds, including organometallic compounds, are known to be generally less toxic than their platinum counterparts, ${ }^{[18-21]}$ and with this in mind, we have developed a new class of organometallic rutheniumEA inhibitors (complexes $\mathbf{1}$ and $\mathbf{2}$ in Scheme 1) that not only bind to the enzyme at the $\mathrm{H}$-site but are also capable of interacting with the reactive cysteine residues of GST P1-1. The organometallic ruthenium fragment is thus tethered to EA at the $\alpha$-acetic functionality, so that the ruthenium center can access the Cys101 residues at the dimer interface upon productively binding the EA unit at the $\mathrm{H}$-site. The compounds were characterized by spectroscopy, and the structure of 1 was confirmed by single crystal X-ray diffraction (Figure 1).

The ability of $\mathbf{1}$ and $\mathbf{2}$ to inhibit GST P1-1 activity was investigated at the protein level. It is known that the most reactive cysteine residues, located at the 47 and 101 positions, are important for modulating the enzymatic activity and can interact with transition-metal-based compounds. ${ }^{[8,10,22,23]}$ Therefore, the wild type and both Cys mutants (Cys47Ser and Cys101Ser) were purified and their residual activity determined after incubation with EA, 1, and 2 (Table 1), showing them to be excellent GST P1-1 inhibitors. 


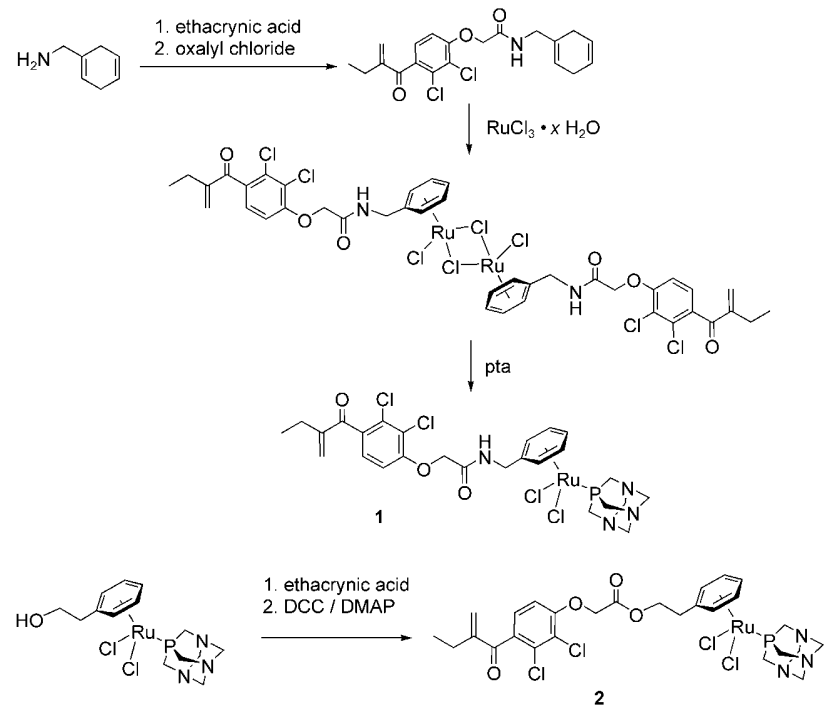

Scheme 1. Synthesis of 1 and 2. pta $=1,3,5$-triaza-7-phosphatricyclo[3.3.1.1] decane, $D C C=N, N$ '-dicyclohexylcarbodiimide, $D M A P=4$-dimethylaminopyridine.

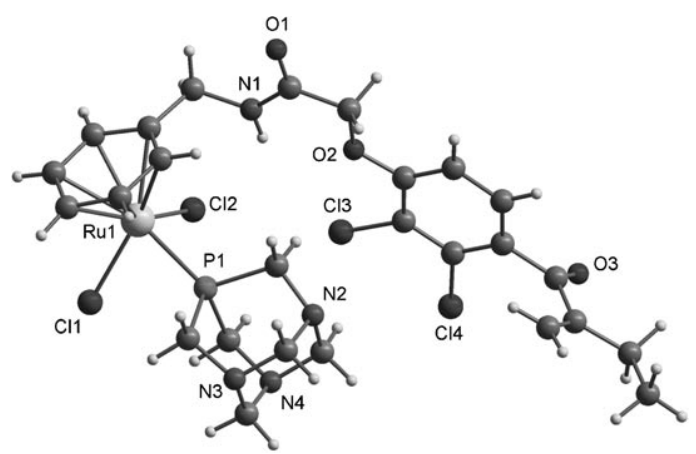

Figure 1. Structure of 1 . Selected bond lengths $[\AA]$ and angles $\left[^{\circ}\right]: \mathrm{Ru}-$

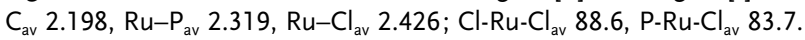

Competitive inhibition studies were further carried out on EA, 1, and 2 using GST P1-1 wild type. The results (Table 1 and the Supporting Information) suggest that $\mathbf{1}$ and $\mathbf{2}$ act as competitive inhibitors towards 1-chloro-2,4-dinitrobenzene (CDNB) and are noncompetitive towards GSH, thus indicating that the complexes bind at the catalytic $\mathrm{H}$-site, in a similar fashion to EA, although the lower $K_{i}$ values (three or four times) of the complexes in comparison to EA suggest that the $\mathrm{Ru}$ center is involved in the inhibition of GST P1-1.

GST P1-1 and the cysteine mutants were treated with equimolar amounts of EA, $\mathbf{1}$, and $\mathbf{2}(20 \mu \mathrm{M}$ active sites versus $20 \mu \mathrm{M}$ compound) in the absence of GSH. The time course

Table 1: Inhibition of activity $I C_{50}$ on GST PI-1 and its cysteine-modified mutants and inhibition constants $K_{\mathrm{i}}$ on GST P1-1.

\begin{tabular}{llllll}
\hline Cmpd & \multicolumn{3}{c}{$\mathrm{IC}_{50}[\mu \mathrm{M}]$} & $K_{\mathrm{i}}^{\mathrm{GSH}}[\mu \mathrm{M}]$ & $K_{\mathrm{i}}^{\mathrm{CDNB}}[\mu \mathrm{M}]$ \\
& $\begin{array}{l}\text { GST P1-1 } \\
\text { wild-type }\end{array}$ & CST P1-1 & CST101Ser P1-1 & & \\
& Cys47Ser & & \\
\hline EA & 12.0 & 19.4 & 42.9 & 22.4 & 11.4 \\
$\mathbf{1}$ & 13.7 & 22.7 & 45.2 & 8.0 & 4.3 \\
$\mathbf{2}$ & 5.9 & 13.4 & 35.2 & 9.6 & 6.5 \\
\hline
\end{tabular}

inactivation profile of $\mathbf{1}$ and $\mathbf{2}$ is significantly different from that of EA (see the Supporting Information). The data suggest that both Cys residues are targets of these compounds, leading to partial loss of activity.

To ascertain the nature of the interaction, the enzyme was incubated with $\mathbf{1}$ and analyzed by ESI-MS to determine any covalent adducts formed (see the Supporting Information). EA forms 1:1 or 1:2 covalent adducts with GST P1-1 when the reaction occurs in the absence of GSH and can bind to Cys47 irreversibly by Michael addition reactions. When GST P1-1 reacts with $\mathbf{1}$, an adduct corresponding to $[\mathrm{GST}+\mathbf{1}-2 \mathrm{Cl}]$ was observed after one hour incubation, while two adducts of lower molecular mass, corresponding to [GST $+(\mathrm{EA}-\mathrm{OH})]$ and $[\mathrm{GST}+(\mathrm{EA}-$ benzylamide $)]$ were obtained after $24 \mathrm{~h}$ incubation. These data suggest that $\mathbf{1}$ originally binds by loss of the two chloride ligands (but is otherwise intact) and is then further cleaved, releasing the ruthenium fragment.

Two separate crystals of GST P1-1 soaked with 1 have been obtained. Both were grown in the same way: type $\mathbf{A}$ was soaked for $24 \mathrm{~h}$ in $5 \mathrm{~mm}$ solution of $\mathbf{1}$, and type $\mathbf{B}$ was treated for $48 \mathrm{~h}$ with solid $\mathbf{1}$. In the type $\mathbf{A}$ structure, $\mathbf{1}$ was observed at the dimer interface close to the thiol of Cys101 from each subunit (Figure 2a). The distance between the sulfur atoms of the Cys101 residues from the two monomers is $1.5 \AA$ smaller than that observed in other GST P1-1 structures, owing to a rotation of the Cys101 side chains on binding $\mathrm{Ru}$ after displacement of the chlorine ligands of $\mathbf{1}$. The S-Ru-S angle of $107.3^{\circ}$ is larger than the $\mathrm{Cl}-\mathrm{Ru}-\mathrm{Cl}$ angle of $88.7^{\circ}$ seen in the small-molecule crystal structure of $\mathbf{1}$, suggesting a more strained conformation caused by protein binding. The arene moiety forms van der Waals interactions with the Glu97 carboxylate of subunit A, the Glu97 and Asp98 carboxylates of subunit B, the side-chain atoms of Cys101 from both subunits, and a water molecule that in turn interacts with residues in the G-site (Arg13 and Ile104) and the GSH ligand of subunit B. In one of the modeled pta ligand positions (where the electron density is less ambiguous), there are van der Waals interactions with the side chains of Arg13 and Glu97 of subunit A, Asp98 of subunit B, Cys101 of both subunits, as well as the GSH ligand in subunit A. The electron density in the dimer interface is consistent with the crystals containing a mixture of (intact) $\mathbf{1}$ and its fragment in which EA has been lost or is mobile. The amide oxygen atom $\mathrm{O} 1$ of intact 1 forms a hydrogen bond with one water molecule, which in turn is hydrogen bonded to another water molecule that interacts with Arg13 and the GSH molecule in one of the $\mathrm{G}$-sites of the enzyme. In addition to $\mathbf{1}$ binding at the dimer interface, a GSH molecule was found bound in the usual way in the $\mathrm{G}$-site of each monomer.

In the type $\mathbf{B}$ structure, EA binds in the $\mathrm{H}$-site of the enzyme with its carboxylic acid group pointing towards the dimer interface, and the ruthenium fragment is no longer present (Figure $2 \mathrm{~b}$ ). The butyryl moiety sits in a pocket surrounded by residues Tyr7, Arg13, Gln51, Leu52, and Ile104. The aromatic moiety of EA forms a $\pi$-stacking interaction with Tyr108 (4.2 $\AA$ separation between the rings). The chlorine atoms form van der Waals interactions with Tyr108 and a nearby water molecule. The inhibitor makes water-mediated contacts between its carboxylic acid 
a)
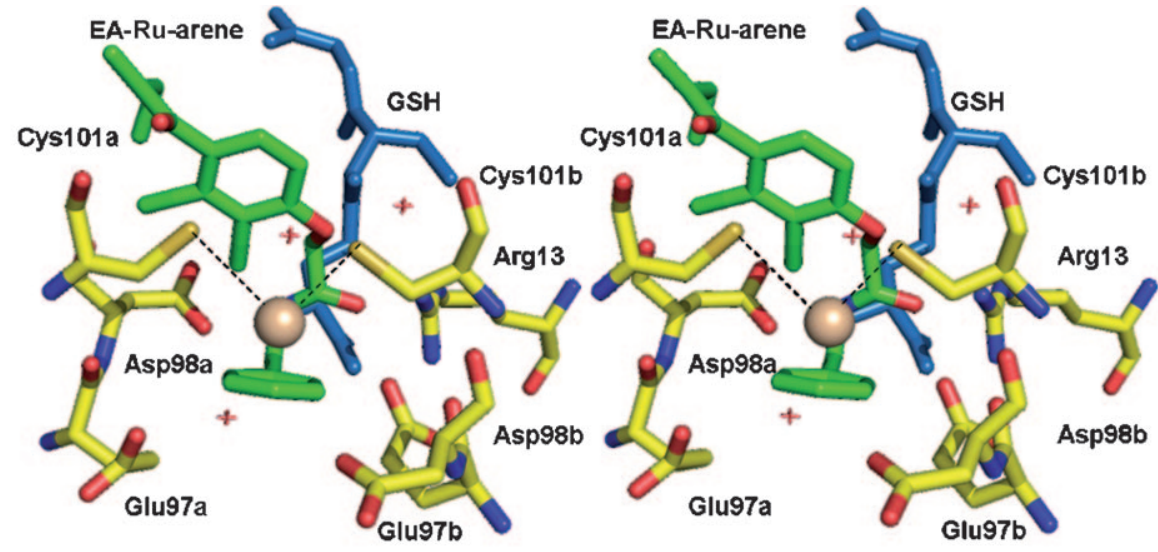

b)

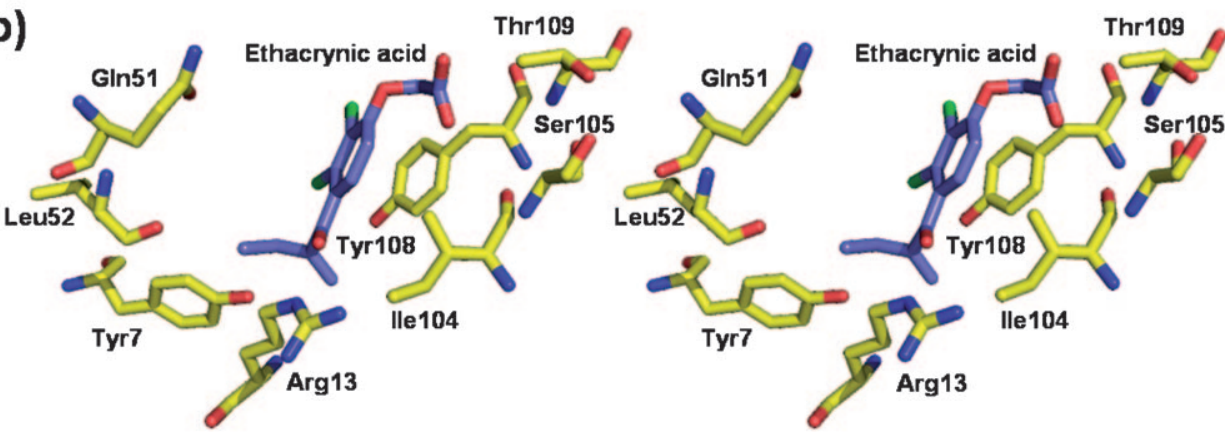

Figure 2. Stereo pictures showing interactions between GST P1-1 and compound 1 as seen by X-ray crystallography. a) Interactions of the ruthenium complex at the GST P1-1 dimer interface. The pta moiety and bonds between the Ru center and the arene ring have been omitted for clarity. The ruthenium center (gray sphere) is bound between the thiol of Cys 101 from each subunit (dashed lines). A GSH molecule is bound in the active site of each monomer (blue bonds). There are also several water-mediated interactions indicated by red crosses. b) Interactions between GST PI-1 and the EA adduct (blue bonds) that is bound in the $\mathrm{H}$-site of subunit $\mathrm{A}$.

moiety and Cys101, Ile104, Ser105, and Thr109 as well as several van der Waals interactions (less than $4 \AA$ ) with Ile104, Ser105, Tyr108, and Thr109.

Superposition of the type B complex onto the GSH complex structure (determined in the same space group: PDB ID 5GSS) $)^{[24]}$ shows that the protein structures are essentially identical with a root-mean-square deviation in $\alpha$ carbon positions of less than $0.3 \AA$. There are no significant movements of side chains in the active site. There is, however, additional electron density extending from the EA unit in the active site, thus suggesting that a larger fragment has bound to the enzyme. However, the density is not clear enough to build anything beyond the EA moiety, and it may also represent alternate conformations of EA binding at lower occupancies. The occurrence of this conformation is consistent with a larger fragment derived from $\mathbf{1}$ binding in the H-site, preventing the EA moiety from binding in the usual modes. The bifunctional binding of 1 to GST P1-1, productively at the $\mathrm{H}$-site and covalently at the dimer interface, represents a novel binding mode that has not been previously observed.

The crystallographic data (for which the type $\mathbf{B}$ crystals were soaked for twice as long as the type $\mathbf{A}$ crystals) are consistent with the ESI-MS data in that breakdown of $\mathbf{1}$ is

\section{Experimental Section} uk/data_request/cif. observed. Indeed, it is possible that EA binding in the $\mathrm{H}$-site dislodges the metal center at the interface through an allosteric effect or that the $\mathrm{Ru}$ center is released from the enzyme over a period of time. Such behavior contrasts with reported organometallic kinase inhibitors in which the entire molecule binds to the enzyme active site and the metal is not released from the ligand shell. ${ }^{[25,26]}$ Nevertheless, for the compounds described herein, cleavage of the ruthenium moiety was expected, and release of ruthenium into the sensitized cancer cell (sensitized by virtue of the GST being inactivated by the EA moiety) should enhance the cytotoxic effect of the compound. From a drug design standpoint, the selective release of at organometallic fragment by GST P11 can be exploited to deliver a cytotoxic payload for targeted chemotherapy. ${ }^{[27]}$ We are currently studying the anticancer activity of $\mathbf{1}$ in vitro and in vivo and intend to report on the outcome of these studies in due course.

All reagents were used as received. Cyclohexa-1,4-dienylmethylamine, ${ }^{[28]}$ 1,3,5-triaza-7-phosphatricyclo[3.3.1.1]decane (pta) ${ }^{[29]}$ and $\left[\left\{\eta^{6}-\mathrm{C}_{6} \mathrm{H}_{5}\left(\mathrm{CH}_{2}\right)_{2} \mathrm{OH}\right\} \mathrm{Ru}(\mathrm{pta}) \mathrm{Cl}_{2}\right]^{[17]}$ were prepared according to literature procedures. Reactions were performed with solvents dried using appropriate columns. Detailed descriptions of the synthesis and characterization of EA-benzylamide, (EA- $\eta^{6}$-benzylamide) dichlororuthenium dimer, $\mathbf{1}$, and $\mathbf{2}$ are given in the Supporting Information.

CCDC 646167 (1) contains the supplementary crystallographic data for this paper. These data can be obtained free of charge from The Cambridge Crystallographic Data Centre via www.ccdc.cam.ac.

The expression and purification of the GST P1-1 wild type and the cysteine mutants (Cys47Ser and Cys101Ser) were performed using the E. coli strain TOP10, as previously described. ${ }^{[30,31]}$

The models have been deposited in the Protein Data Bank (http://www.rcsb.org/pdb) under the filenames 3DD3 and 3DGQ. Further details are also provided in the Supporting Information.

Synthesis and characterization of the compounds, details of inhibition assays of GST P1-1 including time-course inactivation, 
mass spectrometric binding study, and protein crystallization and refinement details are provided in the Supporting Information.

Received: January 12, 2009

Published online: April 27, 2009

Keywords: bioorganometallic chemistry · chemical biology . inhibitors · transferases

[1] J. D. Hayes, J. U. Flanagan, I. R. Jowsey, Annu. Rev. Pharmacol. Toxicol. 2005, 45, 51.

[2] T. M. Buetler, D. L. Eaton, Environ. Carcinog. Ecotoxicol. Rev. 1992, C10, 181.

[3] B. Mannervik, P. Alin, C. Guthenberg, H. Jensson, M. K. Tahir, M. Warholm, H. Jörnvall, Proc. Natl. Acad. Sci. USA 1985, 82, 7202

[4] D. J. Meyer, B. Coles, S. E. Pemble, K. S. Gilmore, G. M. Fraser, B. Ketterer, Biochem. J. 1991, 274, 409.

[5] D. J. Meyer, M. Thomas, Biochem. J. 1995, 311, 739.

[6] H. Dirr, P. Reinemer, R. Huber, Eur. J. Biochem. 1994, 220, 645

[7] M. C. J. Wilce, M. W. Parker, Biochim. Biophys. Acta Protein Struct. Mol. Enzymol. 1994, 1205, 1.

[8] E. Cesareo, L. J. Parker, J. Z. Pedersen, M. Nuccetelli, A. P. Mazzetti, A. Pastore, G. Federici, A. M. Caccuri, G. Ricci, J. J. Adams, M. W. Parker, M. Lo Bello, J. Biol. Chem. 2005, 280, 42172.

[9] A. Dulhunty, P. Gage, S. Curtis, G. Chelvanayagam, P. Board, J. Biol. Chem. 2001, 276, 3319.

[10] A. J. Oakley, M. Lo Bello, M. Nuccetelli, A. P. Mazzetti, M. W. Parker, J. Mol. Biol. 1999, 291, 913.

[11] D. M. Townsend, V. L. Findlay, K. D. Tew, Methods Enzymol. 2005, 401, 287.

[12] H. W. Lo, F. Ali-Osman, Curr. Opin. Pharmacol. 2007, 7, 367.

[13] W. H. Ang, E. Daldini, C. Scolaro, R. Scopelliti, L. JuilleratJeanneret, P. J. Dyson, Inorg. Chem. 2006, 45, 9006.
[14] P. J. Dyson, G. Sava, Dalton Trans. 2006, 1929.

[15] C. G. Hartinger, S. Zorbas-Seifried, M. A. Jakupec, B. Kynast, H. Zorbas, B. K. Keppler, J. Inorg. Biochem. 2006, 100, 891.

[16] M. A. Jakupec, M. Galanski, V. B. Arion, C. G. Hartinger, B. K. Keppler, Dalton Trans. 2008, 183.

[17] C. Scolaro, A. Bergamo, L. Brescacin, R. Delfino, M. Cocchietto, G. Laurenczy, T. J. Geldbach, G. Sava, P. J. Dyson, J. Med. Chem. 2005, $48,4161$.

[18] C. S. Allardyce, A. Dorcier, C. Scolaro, P. J. Dyson, Appl. Organomet. Chem. 2005, 19, 1.

[19] M. Galanski, V. B. Arion, M. A. Jakupec, B. K. Keppler, Curr. Pharm. Des. 2003, 9, 2078.

[20] I. Kostova, Curr. Med. Chem. 2006, 13, 1085.

[21] P. J. Dyson, C. Hartinger, Chem. Soc. Rev. 2009, 38, 391.

[22] W. H. Ang, A. De Luca, C. Chapuis-Bernasconi, L. JuilleratJeanneret, M. Lo Bello, P. J. Dyson, ChemMedChem 2007, 2, 1799.

[23] G. Ricci, G. Del Boccio, A. Pennelli, M. Lo Bello, R. Petruzzelli, A. M. Caccuri, D. Barra, G. Federici, J. Biol. Chem. 1991, 266, 21409.

[24] A. J. Oakley, M. Lo Bello, A. Battistoni, G. Ricci, J. Rossjohn, H. O. Villar, M. W. Parker, J. Mol. Biol. 1997, 274, 84.

[25] N. Pagano, J. Maksimoska, H. Bregman, D. S. Williams, R. D. Webster, F. Xue, E. Meggers, Org. Biomol. Chem. 2007, 5, 1218.

[26] J. E. Debreczeni, A. N. Bullock, G. E. Atilla, D. S. Williams, H. Bregman, S. Knapp, E. Meggers, Angew. Chem. 2006, 118, 1610; Angew. Chem. Int. Ed. 2006, 45, 1580.

[27] K. D. Tew, Expert Opin. Investig. Drugs 2005, 14, 1047.

[28] W. H. Ang, E. Daldini, L. Juillerat-Jeanneret, P. J. Dyson, Inorg. Chem. 2007, 46, 9048 .

[29] D. J. Daigle, Inorg. Synth. 1998, 32, 40.

[30] A. Battistoni, A. P. Mazzetti, R. Petruzzelli, M. Muramatsu, G. Federici, G. Ricci, M. Lo Bello, Protein Expression Purif. 1995, 6, 579.

[31] M. Lo Bello, A. Battistoni, A. P. Mazzetti, P. G. Board, M. Muramatsu, G. Federici, G. Ricci, J. Biol. Chem. 1995, 270, 1249. 